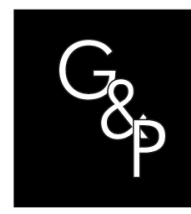

\title{
Visual attention of experts and novices to a critical industrial maintenance task
}

\author{
Atenção visual de trabalhadores experientes e novatos em uma \\ tarefa crítica de manutenção industrial
}

\author{
Marinilda Lima Souza ${ }^{1}$ (D), Camila de Sousa Pereira-Guizzo ${ }^{1}$ (D), Alex Álisson Bandeira Santos ${ }^{1}$ (D), \\ José Maria León-Rubio² \\ ${ }^{1}$ Centro Universitário SENAI CIMATEC, Salvador, BA, Brasil. E-mail: marinilda.lima@fieb.org.br; \\ camila.pereira@fieb.org.br; alex.santos@fieb.org.br \\ 2Universidad de Sevilla, Sevilha, Espanha. E-mail: jmleon@us.es
}

How to cite: Souza, M. L., Pereira-Guizzo, C. S., Santos, A. A. B., \& León-Rubio, J. M. (2021). Visual attention of experts and novices to a critical industrial maintenance task. Gestão \& Produção, 28(3), e5050. https://doi.org/10.1590/1806-9649-2021v28e5550

\begin{abstract}
In the industrial maintenance field, critical tasks are activities that can endanger operating processes and cause serious accidents if not performed correctly. These tasks are typically performed by professionals with a considerable level of knowledge and rely on prescribed procedures that flag the task, drawing the attention of task performers. Given the importance of reviewing work procedures and monitoring tasks for human error prevention, this study analyzed similarities and differences in the visual attention of expert and novice task performers while following procedures with and without flagging of a critical task. The study included 48 maintenance professionals, divided into two groups of performers: experts and novices. For attention analysis, eye-tracking technology was used to monitor their observation during the work procedure, recording data on time to first fixation, total fixation time and number of visits. The results indicate that in the procedure without flagging of the critical task, the numbers of fixations on and visits to the stages of the task were higher in the novice than in the expert group. In the flagged procedure, the visual attention of experts and novices was similar when considering all stages of the task. In conclusion, the tasks must be revised between the two groups, and the flagged procedure can be used as a guide for work monitoring, helping experts or novices to more easily select relevant information.
\end{abstract}

Keywords: Attention; Industrial maintenance; Eye tracking.

Resumo: Tarefas críticas, na área de manutenção industrial, são atividades que se não executadas corretamente podem colocar em risco o processo operacional e provocar acidentes graves. Geralmente, essas tarefas são executadas por profissionais com nível considerável de conhecimento, devendo ainda contar com procedimentos prescritos que sinalizem a tarefa, direcionando a atenção dos executantes. Considerando a importância da revisão dos procedimentos de trabalho e do monitoramento das tarefas para prevenção de erros humanos, este estudo teve como objetivo analisar as semelhanças e diferenças na atenção visual de executantes experientes e novatos usando procedimentos sem e com sinalização de uma tarefa crítica. A pesquisa contou com a participação de 48 profissionais da área de manutenção, divididos em dois grupos de executantes: experientes e novatos. Para análise da atenção, foi usada a tecnologia eye tracking (rastreador ocular), que registrou os dados do instante de

Received July 16, 2019 - Accepted Feb. 1, 2020

Financial support: None.

This is an Open Access article distributed under the terms of the Creative Commons Attribution License, which permits unrestricted use, distribution, and reproduction in any medium, provided the original work is properly cited. 
primeira fixação, tempo total de fixação e número de visitas, durante a observação dos executantes no procedimento de trabalho. Os resultados indicam que no procedimento sem sinalização, os novatos obtiveram maior número de fixações e de visitas nas etapas da tarefa. No procedimento sinalizado, a atenção dos experientes e novatos ocorreu de modo mais semelhante, contemplando ainda todas as etapas da tarefa. Conclui-se que há a necessidade de revisão das tarefas entre os dois grupos e que o procedimento sinalizado pode servir como guia para monitoramento do trabalho, contribuindo para que o executante experiente ou novato consiga selecionar informações relevantes mais facilmente.

Palavras-chave: Atenção; Manutenção industrial; Eye tracking.

\section{Introduction}

Modern production systems, aimed at managing alarms and risky operations, have increasingly adopted safety in their processes. From this perspective, the industrial maintenance sector requires the availability of reliable equipment and systems, environmental preservation and, above all, operational and personal safety (Kardec \& Nascif, 2005; Sheikhalishahi et al., 2016). However, industrial maintenance must still overcome many challenges to reduce risk and human error, especially in critical tasks (Carvalho \& Menegon, 2014; French et al., 2011; Romo, 2013; Sheikhalishahi et al., 2016).

One of the critical tasks of industrial maintenance consists of installing and testing mechanical seals used in the chemical and petrochemical industry. The American Petroleum Institute (API), through API Standard 682 (API, 2004), standardized the manufacturing, installation and testing of mechanical seals in centrifugal and rotary pumps. Mechanical seals are dynamic devices designed to prevent fluids from crossing the interface between two relatively moving radial annular surfaces (Lima, 2003). A mechanical seal is installed in a seal box or seal chamber to prevent or avoid leakage of pressurized gas or liquid. When installing the mechanical seal, recommendations for safety precautions while handling the component should be followed.

Centrifugal pumps are the most commonly used pumps in production processes of the chemical and petrochemical industries, and they operate with the most diverse types of products. In the petrochemical industry, the setting of this study, centrifugal pumps operate with high-risk products such as flammable gases, toxic gases and corrosive substances, among others. Accordingly, the activity of assembling and installing the mechanical seal is critical for ensuring the integrity of the sealing system. In other words, improperly performing the task of assembling and installing the mechanical seal can lead to severe accident risks, with consequences for the physical integrity of the professionals involved in the execution of the task as well as for the environment.

In the context of industrial maintenance, critical tasks are activities that, if not executed correctly, can not only endanger the operational process but also cause serious incidents or accidents. These tasks are typically executed by professionals with considerable knowledge and competence and that should be performed following prescribed procedures that flag the execution of the task. Given the importance of these work procedures for preventing human errors and the need for monitoring worker performance to identify task review and professional training requirements, this study analyzes similarities and differences in the visual attention of expert and novice task performers using procedures with and without flagging of the mechanical seal assembly and installation task. 
The first section introduces the topic of the article and presents the objectives of this study. The second section comprises a literature review. The third section describes the methodological procedures, detailing the techniques and the selection of the study variables. The fourth section analyses and discusses the results. Last, the study concludes by considering future perspectives.

\section{Literature review}

Although the importance of a systemic approach to safety culture that also encompasses organizational structure is recognized, focusing on specific interactions between humans, work and artifacts remains relevant (Henriqson \& Saurin, 2013; Reason, 1990). In this interaction, worker attention stands out among several cognitive aspects for its key role in reducing risks and human errors in production processes (Chelazzi et al., 2013; Duchowski, 2002; French et al., 2011; Giesbrecht et al., 2014; Henriqson \& Saurin, 2013).

According to Bear et al. (2008, p. 644), "[...] the state of selectively processing simultaneous sources of information is known as attention". Attention selectively controls all information received through the body's sensory channels, selecting that which is essential for executing a task and ignoring all others (Bear et al., 2008; Brandão, 2004). Attention selectivity regulates and controls interferences caused by irrelevant stimuli (Montes et al., 2016). Visual attention is a mechanism that selects a location or set of locations containing relevant perceptual information within a scene (Hollingworth \& Maxcey-Richard, 2013). In the visual system, attention span can have positive effects on visual processing speed or decision-making time (Bear et al., 2008).

Thus, attention increases the likelihood of a prompt and accurate response to stimuli (Montes et al., 2016; Sternberg, 2010). Inattention can cause failures in task learning and in memory acquisition and retrieval (Izquierdo, 2011) and can lead individuals to make more mistakes (Montes et al., 2016). Therefore, researching worker attention makes it possible to understand how workers direct their cognitive resources towards processing the information that matters in performing their work activities and how those mechanisms affect task performance.

Sternberg (2010) highlights that several factors affect the attention process, including the type of task, for example. Highly difficult, complex or new tasks demand more attention resources than do easy, simple and well-known tasks. Haider \& Frensch (1999) further argue that individuals learn to differentiate relevant from irrelevant information as they become more experienced in a task, focusing on relevant stimuli. Therefore, experience may affect attention and accelerate the reaction time in executing a specific task and in decision-making (van den Bogert et al., 2014; Dzeng et al., 2016).

In this context, some studies have investigated how task performance varies with the level of experience, using eye-tracking technology (Charness et al., 2001; Dzeng et al., 2016; Gómez-Valadés et al., 2013; Jarodzka et al., 2010). Eye tracking measures eye movements when stimuli are presented on a fixed computer screen or mobile device. Eye-tracking analysis can provide information on eye movement events, including eye fixations and saccades, considering parameters such as location and time (Crundall \& Underwood, 2011). Eye fixation location indicates the focal point of attention, whereas eye fixation duration can indicate the degree of cognitive difficulty and attention (Dzeng et al., 2016). Conversely, saccades are rapid and sudden eye movements that indicate the focal orientation of the eyes as they shift from one point 
of interest to another, but no visual information is recognized during these rapid movements (Dzeng et al., 2016).

In an eye-tracking study focused on visual search strategies among expert and novice drivers during the presentation of driving scenes, Gómez-Valadés et al. (2013) found that the group of experts showed a higher number and longer time of fixations on relevant stimuli for driving in traffic than did the group of novices. In turn, the group of novices showed a higher number and longer time of fixations on locations irrelevant for driving.

In another eye-tracking study, Dzeng et al. (2016) compared visual search patterns between experienced and novice workers in hazard identification in civil construction. The results indicated that experience helped experienced workers assess obvious and unobvious hazards significantly faster than novice workers. The authors also noted that experienced workers showed a lower number of fixations when assessing hazards and that their scan paths were more consistent than those of novice workers, suggesting that the former were more confident in identifying hazards than were the latter. Another key finding of this study was that expert workers assessed high-risk targets earlier than did novice workers.

In their study, Jarodzka et al. (2010) observed that experts were able to perform a specific task using visual search patterns more accurately and on average faster than were novices. The results also showed that experts attended more to relevant aspects of the stimulus than did novices, using more heterogeneous task approaches and using knowledge-based shortcuts.

These studies suggest that mapping the visual attention of expert workers by eye tracking may help in designing work procedures more focused on worker expertise and task specificities and in training novices. According to Duchowski (2002), if the eye movement patterns of expert operators is recurrent and systematic, this information can be used to train novice operators. Identifying recurrent and systematic patterns is important because experience can have undesirable effects on occupational safety, such as overconfidence. Accordingly, overconfidence increases the likelihood of using shortcuts when performing tasks, leading to unsafe behaviors (Bauer \& Weiner, 2010; Martins, 2008).

In industrial production processes, disparities between prescribed procedures and actual work can lead workers to adopt various strategies to mitigate such gaps in practice, as shown by Silva \& Camarotto (2012). Embrey (2000) also found evidence of a wide disparity between the formal prescribed procedures in an organization and how the work is actually performed. These gaps may compromise occupational safety because the lack of knowledge sharing and task standardization, as well as cognitive overload, may lead to accidents (Carvalho \& Menegon, 2014; French et al., 2011; Ikuma et al., 2014; Le et al., 2014; Silva \& Camarotto, 2012).

API (2001) indicates the following factors as the main causes of increased likelihood of error in equipment maintenance activities in the chemical and petrochemical industries: insufficient knowledge, poor flagging, layout errors, excessive mental tasks, inadequate tools and ineffective procedures. According to API (2001), errors in work procedures may create the conditions for workers to incorrectly execute activities, which significantly increases the likelihood of errors in tasks with some degree of complexity, resulting in incidents or accidents.

According to Carvalho \& Menegon (2014) and Embrey (2000), one of the main reasons why prescribed procedures are not used is the difficulty in translating and decoding the specificities of a task using methods for procedure design. To overcome 
this obstacle, API (2001) suggests that workers who perform a task and know how to execute it should help to write the corresponding procedure. In addition to including experts in the design of work procedures, Pallerosi et al. (2011) recommend training maintenance teams as a strategy for monitoring tasks and for keeping workers motivated and updated.

Given the numerous possibilities for assessing and applying eye-tracking technology, the number of published empirical studies analyzing the visual attention of petrochemical industry workers in critical maintenance tasks using this technology is surprisingly low thus far. Eye-tracking technology has significantly improved in recent years, enabling sophisticated methods for recording eye movements and becoming an interesting tool for researching cognition, including attention (Boyer \& Wang, 2018; Guerra-Carrillo \& Bunge, 2018; Ramey et al., 2019) and other variables such as social behavior (van Rijn et al., 2019), in addition to allowing several applications in academia and in the industrial sector (Koller et al., 2012). For example, some studies have used eye-tracking technology to assess training programs or learning in the industrial setting (Salehi et al., 2018; Vijayan et al., 2018).

Thus, the objective of this study was to compare, using eye tracking, the visual attention of experts and novice oil industry workers during observation of an on-screen critical maintenance task (mounting and installing mechanical seals on centrifugal pumps to prevent gas or liquid leakage), with and without flagging of the task steps. The results may help to generate transferable knowledge in the field of occupational safety and professional training in the industrial maintenance sector, enabling the development of safer work procedures and training processes more adapted to tasks performed in the sector.

\section{Methods}

\subsection{Participants}

In total, 48 maintenance workers in the petrochemical industry who perform mechanical seal assembly and installation participated in this study. All participants worked in the same company, located in the state of Bahia, Brazil. The participants were divided into two groups: EG - the expert group (workers with more than 10 years of experience performing the task); and NG - the novice group (workers with up to two years of experience performing the task). Table 1 presents the sample characteristics.

Table 1. Characteristics of the participants from the expert (EG) and novice (NG) groups.

\begin{tabular}{ccc} 
& EG & NG \\
\hline Number of participants & 27 & 21 \\
\hline Age range & 36 to 63 years & 22 to 33 years \\
\hline Educational level & $68 \%$ technical level & $64 \%$ technical level \\
\hline Sex & 27 Men & 19 Men 2 Women \\
\hline Average task experience & $M=15.5$ years $(\mathrm{SD}=8.23)$ & $M=1.4$ years $(\mathrm{SD}=0.53)$ \\
\hline $\mathrm{SD}=$ standard deviation. & &
\end{tabular}

As shown in Table 1, the EG consisted of 27 participants, with ages ranging from 36 to 63 years and with an average of 15.5 years of experience performing the task. 
The NG consisted of 21 participants, with ages ranging from 22 to 33 years and with an average of one year and four months of experience performing the task.

\subsection{Materials and equipment}

This study used a work procedure of the maintenance sector (mechanical seal installation and testing) and an eye tracker, as detailed below.

\subsubsection{Prescribed work procedure}

The work procedure used in this study was developed by Figueiroa \& Souza (2011) with the participation of experts in assessing the stages of assembling and installing a mechanical seal in centrifugal pumps. The procedure details, step by step, the work practices of maintenance workers using API (2001) as a reference, specifically the topic on task simplification and, especially, the use of pictorial language instead of traditional narrative and descriptive styles. For this study, only an excerpt of this work procedure was used, that is, the image of the pump that contains the structures for mounting and installing the mechanical seal. Figure 1 shows the excerpt from the work procedure, without flagging the stages of the task, which was used in this study.
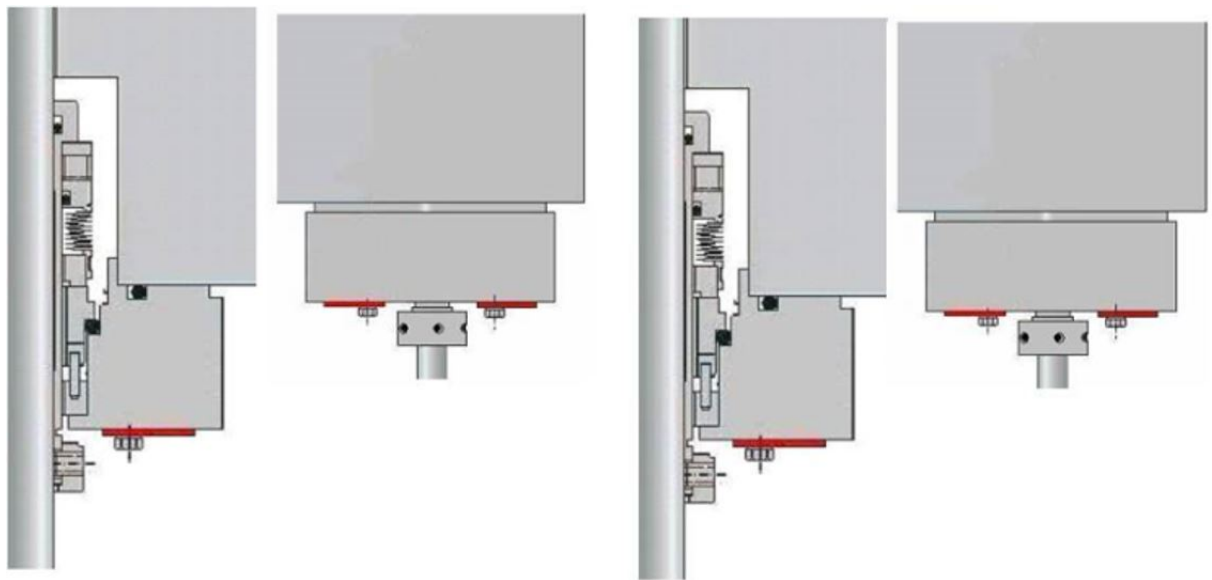

Figure 1. Nonflagged procedure. Source: Figueiroa \& Souza (2011).

In turn, Figure 2 illustrates the work procedure flagging the stages in which the task should be performed. These stages were flagged in the procedure because the mechanical seal was recurrently not locked after mounting the seal, which caused rework and a risk of incidents or accidents. Flagging was a way to draw attention to the need for completing all mechanical seal assembly and installation steps (Figueiroa \& Souza, 2011). 

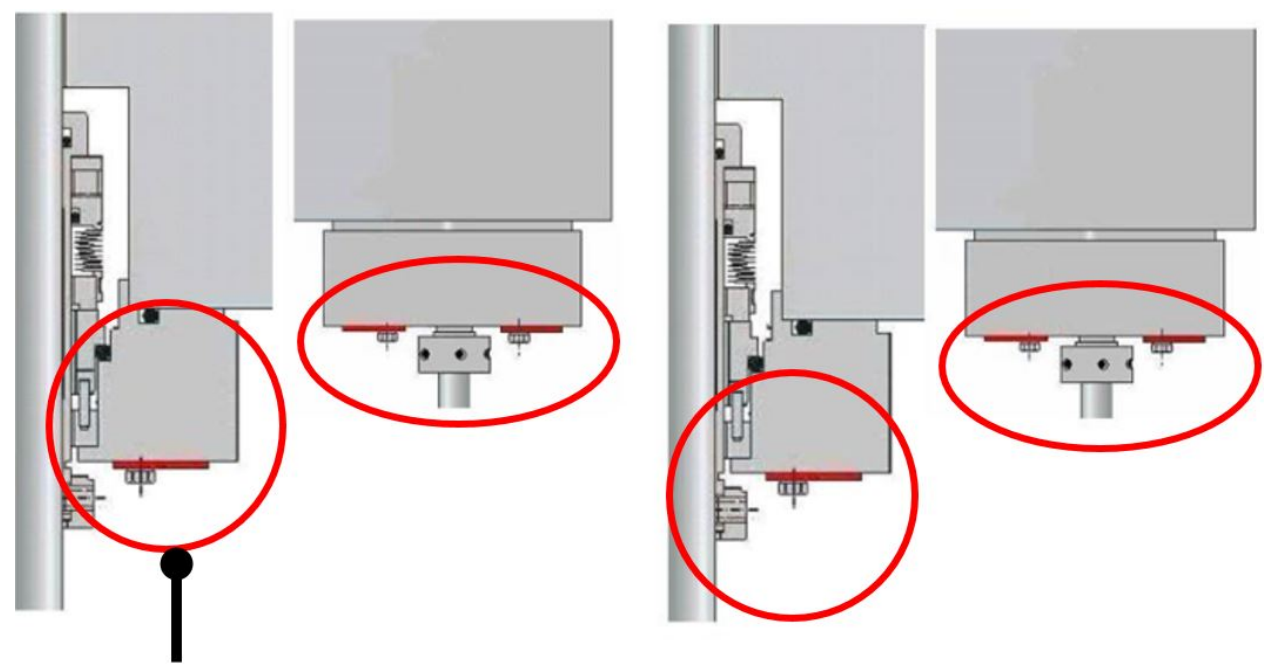

\section{Flagging}

Figure 2. Flagged procedure. Source: Figueiroa \& Souza (2011).

Thus, two models of prescribed work procedures were used to collect data for the present study: with and without flagging. Hence, the experiment was divided into two phases: (a) experts and novices using the nonflagged procedure; and (b) experts and novices using the flagged procedure.

\subsubsection{Eye tracking}

The eye tracker used in this study was a table-mounted, screen-based eye tracker, model X30/60, imported from Tobii Technology, with registration and license numbers. This eye tracker can be mounted on a laptop or computer screen. For real-time data collection, the device processes images and records a video of the scene (Tobii, 2013). The modular system can take accurate measurements using the pupil (saccade and fixation points) to scale human eye movements. Accurate measurements are taken at varying sampling rates, and accuracy is calculated as the root-mean-square (RMS) of successive samples. The eye-tracking software Tobii Studio, which generates metrics and graphs from dynamic areas of interest (AOI), was used for data visualization and analysis.

The following metrics were selected for data analysis in this study. (a) Time to first fixation refers to the time, measured in seconds, from the onset of stimulus viewing to the onset of the first fixation on a specific AOI. The analysis of the time to first fixation reveals the search strategy of the group, suggesting that subjects seek to view first what is most important (Barreto, 2012; Charness et al., 2001). (b) Number of fixations refers to the participant's number of fixations on an AOI. According to Duchowski (2007), the number of fixations indicates the targets fixed when viewing a scene. When analyzing the number of fixations, Barreto (2012) identified that a higher frequency of fixation on a specific area may suggest information seeking, that is, higher uncertainty in recognizing a target item. Rayner (1998) also highlights that the lower the number of fixations is, the more efficient the search process will be. (c) Number of visits refers 
to the number of visits to AOls. Number of visits is related to the need to confirm information.

\subsection{Data collection}

This study was conducted in a closed environment to avoid ergonomic risks and to ensure the quality of the data collected, carefully controlling parameters such as lighting, temperature, workstation and background noise, among others. For the purpose of this study, the experimental environment was set up as shown in Figure 3.

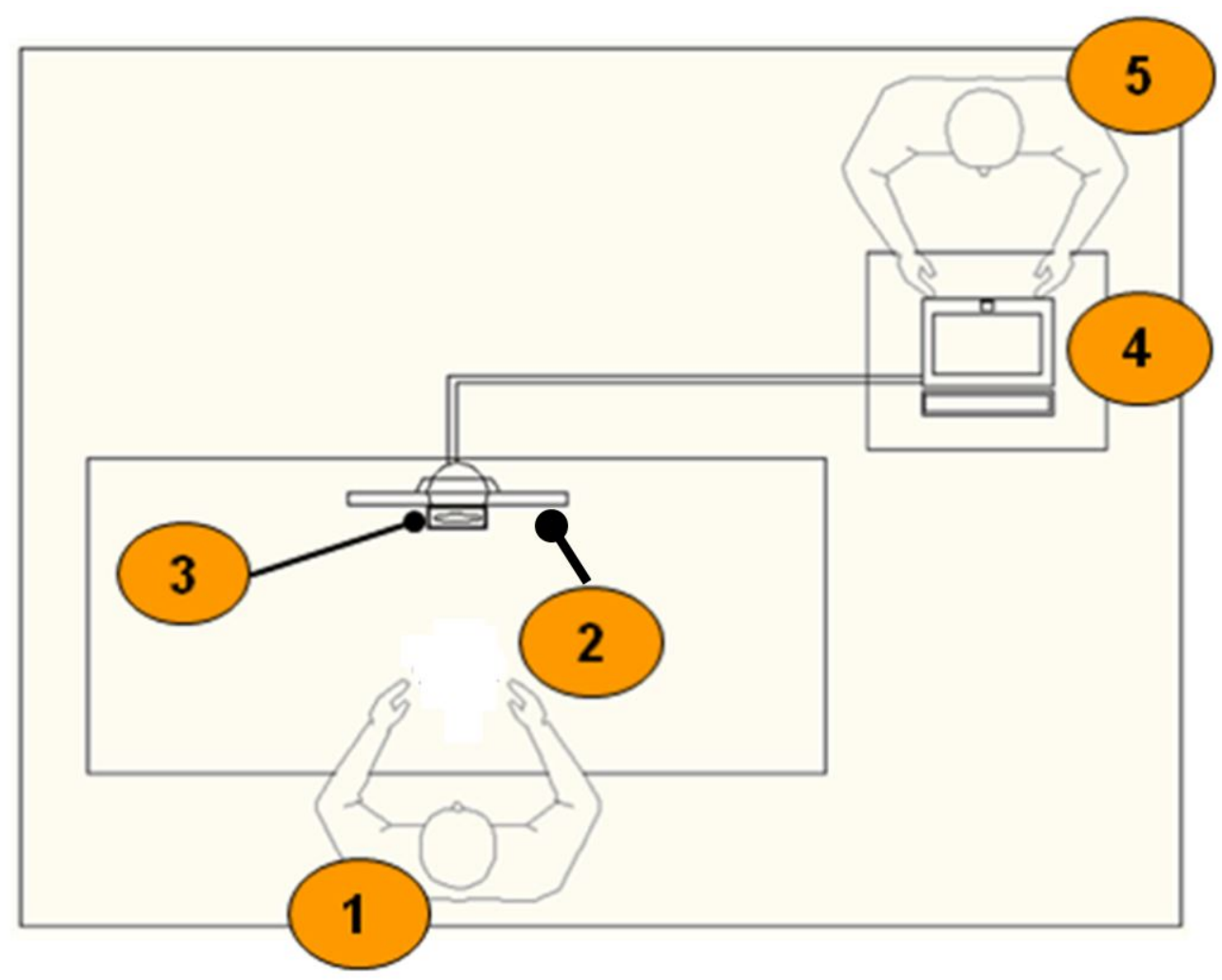

Figure 3. Experimental environment set up. Source: Authors. Legend: (1) Participant; (2) Procedure screen; (3) Eye tracker; (4) Laptop computer with data analysis software; (5) Researcher monitoring the experiment.

The prescribed work procedure for mounting and installing a mechanical seal was viewed on a screen. After calibrating the eye tracker, the participants were asked to locate "the most relevant points that must be observed and inspected when mounting and/or installing a mechanical seal".

First, with both groups, the experiment was performed using the nonflagged procedure. Then, the same instructions were given for the flagged procedure. The experiment was conducted in individual sessions with a total time of approximately three minutes per participant. 


\subsection{Data treatment}

The AOls for eye movement analysis in the eye-tracking system were defined using the mechanical seal assembly and installation stages as criteria (Figure 4).
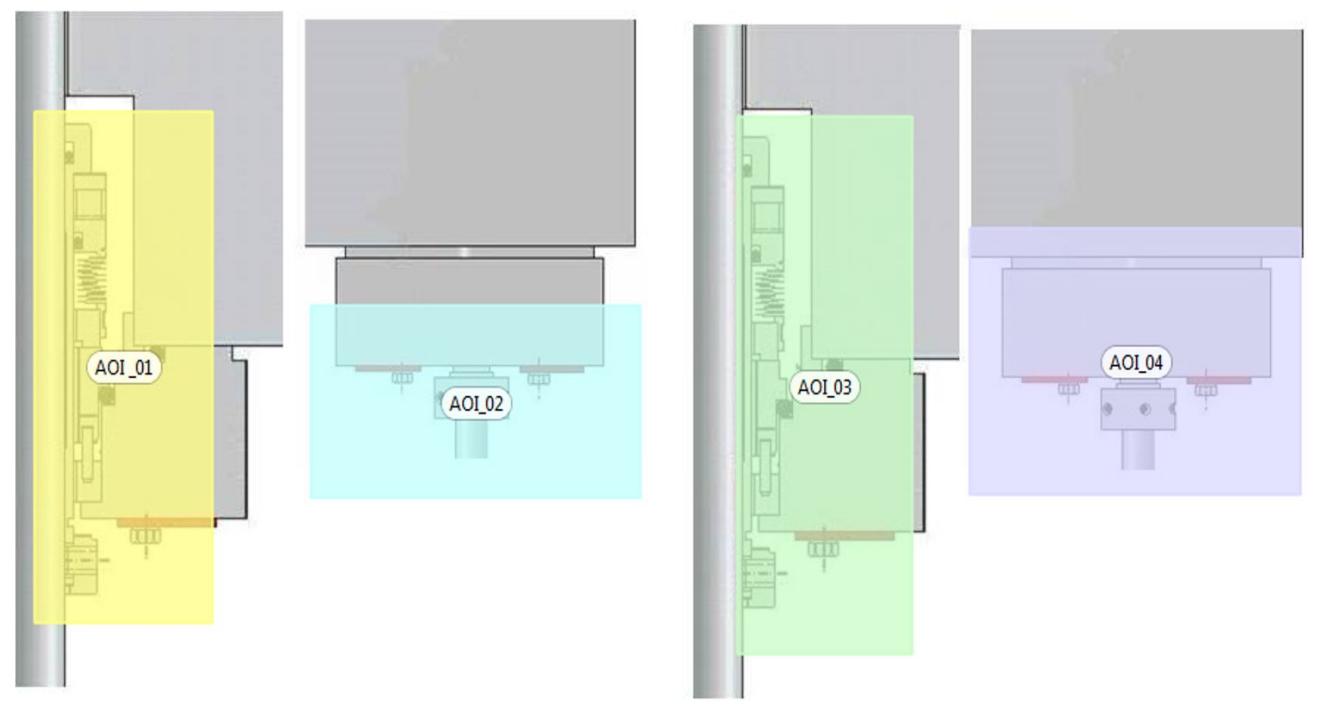

Figure 4. Definition of AOls for task analysis. Source: Authors.

As shown in Figure 4, the functional and crucial elements and/or components for operating the system were presented in AOI_01 and AOI_03: bellows and primary and secondary seals. Conversely, AOI_02 and AOI_04 detail the elements responsible for assurance and safety of the mechanical seal assembly and installation: the lock and the collar.

The eye-tracking metrics - fixation time, number of fixations and number of visits were analyzed considering the initial performance time (five seconds) and the total time of the experiment (approximately three minutes). These metrics were investigated in the EG and NG, in both the flagged and nonflagged procedures. These results were analyzed by descriptive statistical analysis and presented in table and graph formats.

The graph was generated using the analysis software of the eye-tracking system, which creates a heatmap, among other graphs. The heatmap uses shades of different colors to show the number of fixations or how long participants viewed specific areas of the image. The points with the highest number of fixations or with the longest viewing times are represented with darker shades of warmer colors, usually red. In turn, the points with the lowest number of fixations and the shortest viewing times are represented by lighter shades of cooler colors, such as green, with different levels (Tobii, 2013).

\section{Results and discussion}

The analysis of the results was divided into two topics: (a) onset of task viewing with the flagged and nonflagged procedures (in the expert and novice groups) and (b) task viewing with the flagged and nonflagged procedures (in the expert and novice groups) over the total time. 


\subsection{Onset of task viewing with the flagged and nonflagged procedures in the expert and novice groups}

At this stage of the analysis, a sampling time of five seconds was used to assess the initial fixations because some eye-tracking studies suggest that the essence of the scene or user stimulus can be analyzed based on the result obtained at the onset of viewing (Charness et al., 2001; Duchowski et al., 2001; Duchowski, 2002; Rayner, 1998). In other words, useful information is immediately acquired in the first fixations. The results obtained with the initial fixations (five seconds) on AOls are presented in Table 2.

Table 2. Analysis of fixations in the first five seconds.

\begin{tabular}{|c|c|c|c|c|c|c|c|c|}
\hline & \multicolumn{4}{|c|}{ Nonflagged Procedure } & \multicolumn{4}{|c|}{ Flagged Procedure } \\
\hline & \multicolumn{2}{|c|}{ EG } & \multicolumn{2}{|c|}{ NG } & \multicolumn{2}{|c|}{ EG } & \multicolumn{2}{|c|}{ NG } \\
\hline & AOI & Result & AOI & Result & AOI & Result & AOI & Result \\
\hline $\begin{array}{l}\text { Time to } \\
\text { first } \\
\text { fixation }\end{array}$ & AOI_03 & $0.34 \mathrm{~s}$ & AOI_02 & $0.15 \mathrm{~s}$ & AOI_02 & $0.24 \mathrm{~s}$ & AOI_03 & $0.23 \mathrm{~s}$ \\
\hline $\begin{array}{l}\text { Number } \\
\text { of } \\
\text { fixations }\end{array}$ & AOI_01 & 3 & AOI_02 & 3 & AOI_01 & 3 & AOI_01 & 2 \\
\hline $\begin{array}{l}\text { Number } \\
\text { of visits }\end{array}$ & AOI_01 & 1 & AOI_02 & 3 & AOI_01 & 1 & AOI_01 & 1 \\
\hline
\end{tabular}

Legend: $A O I=$ Area of Interest; $E G=$ Expert Group; NG = Novice Group.

As shown in Table 2, in the nonflagged procedure, the NG clearly views, in the initial seconds, the stage of the mechanical seal locking system (AOI_02), whereas the experts, in the first fixations, search for the area with the functional elements of the sealing system (AOI_03). The experts start by viewing (AOI_03) the stage that should be assembled first and then move to the locking system (AOI_02). Even without flagging the stages of the task, the EG recognizes that to start mounting and installing the mechanical seal, the sealing system stage (AOI_03) must precede the locking system stage (AOI_02). It is inferred that the experts attended to the stages of the task, even without flagging.

In terms of the numbers of fixations and visits in the nonflagged procedure, the EG had the highest number of fixations on AOI_01, although the experts did not need to return to this area more than once. Because a higher frequency of fixation on a given area may suggest information seeking or higher uncertainty in recognizing a target item (Barreto, 2012), regardless of how long the experts focused on AOI_01 (bellows), they did not need to return to confirm the information. In turn, the NG fixed their eyes on AOI_02 (lock), which was also the fixation area in the first five seconds, and needed to return to this $\mathrm{AOI}$ to confirm the information at this stage of the locking system more often than did the experts. This finding suggests that this stage of the activity (AOI_02) generates doubt in novices in the nonflagged procedure, supporting the analysis by Sternberg (2010), who argues that new tasks may require more attention resources than well-known tasks.

Conversely, in the flagged procedure, the results reverse at the onset of viewing: the NG fixed their eyes, at first, on the sealing system (AOI_03) and experts on the locking system (AOI_02). Attention in the initial test of the task with the flagged 
procedure was not the same as in the nonflagged procedure, in either group; that is, the AOls reversed from one procedure to the other. This finding supports the importance of assessing the recurrent and systematic eye movement pattern of experts when analyzing this expertise for training novices (Duchowski, 2002) because, in this second test, the EG had a different result. Thus, this finding suggests the need for revising the most relevant points that should be observed and inspected during the assembly and/or installation of a mechanical seal, including for the EG, and assessing the possibility of enhancing the flagged procedure by including clues for retrieving this information to facilitate memory recall (Izquierdo, 2011).

In terms of the number of fixations and number of visits in the flagged procedure, both experts and novices kept their attention on the same stage and did not return to this stage to confirm the information because they visited AOI_01 only once. This result indicates that the flagged procedure, despite needing revisions or updates, may be used as a guide for experts and novices to quickly and accurately respond to stimuli, making them use more systematized task approaches from the beginning of the activity, corroborating literature data (API, 2001; Bear et al., 2008; Embrey, 2000; French et al., 2011).

\subsection{Task viewing with the nonflagged and flagged procedures in the expert and novice groups in the full session}

Considering the viewing of the full task, Figure 5 illustrates the attention of the workers during the nonflagged procedure, through the eye-tracking heatmap, which displays areas with varying intensity in the form different color shades.

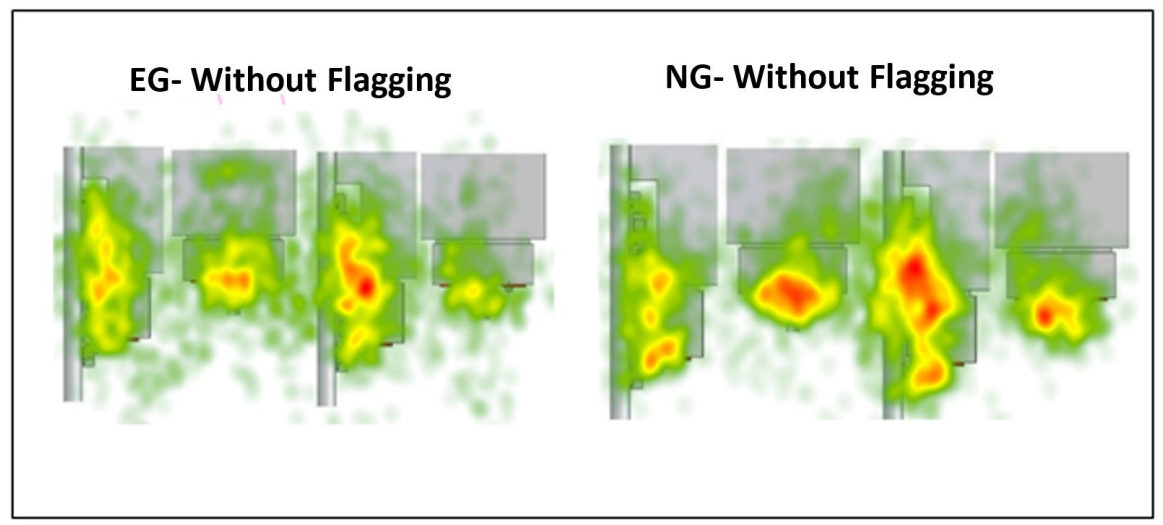

Figure 5. Heatmap of the EG and NG for the nonflagged procedure. Source: Authors.

As shown in Figure 5, the experts focused their attention more on the area of the sealing system (AOI_03), similarly to the result identified in the initial five seconds of the task viewing with the nonflagged procedure in this group. The novices, in the full session, focused their attention on both AOI_02 and AOI_03. Considering that AOI_03 is a key stage of the task for preventing the passage of fluid (sealing), both groups showed attention to this step, even without flagging.

However, the nonflagged procedure may have raised doubts among the novices, as shown in Figure 5. Differences in the red shade of AOls between groups, which was darker in the NG, express differences in the numbers of fixations on and visits to stages 
of the activity, which were higher among novices. The NG showed a longer fixation time and return to the area of interest for confirmation more often than did the EG because novices feel less confident in selecting the correct information, corroborating the results from other studies that also investigated differences between experts and novices (Barreto, 2012; Dzeng et al., 2016; Gómez-Valadés et al., 2013; Haider \& Frensch, 1999; Jarodzka et al., 2010; Rayner, 1998; Salehi et al., 2018).

Regarding the results of the flagged procedure, Figure 6 illustrates the attention of workers in both groups.

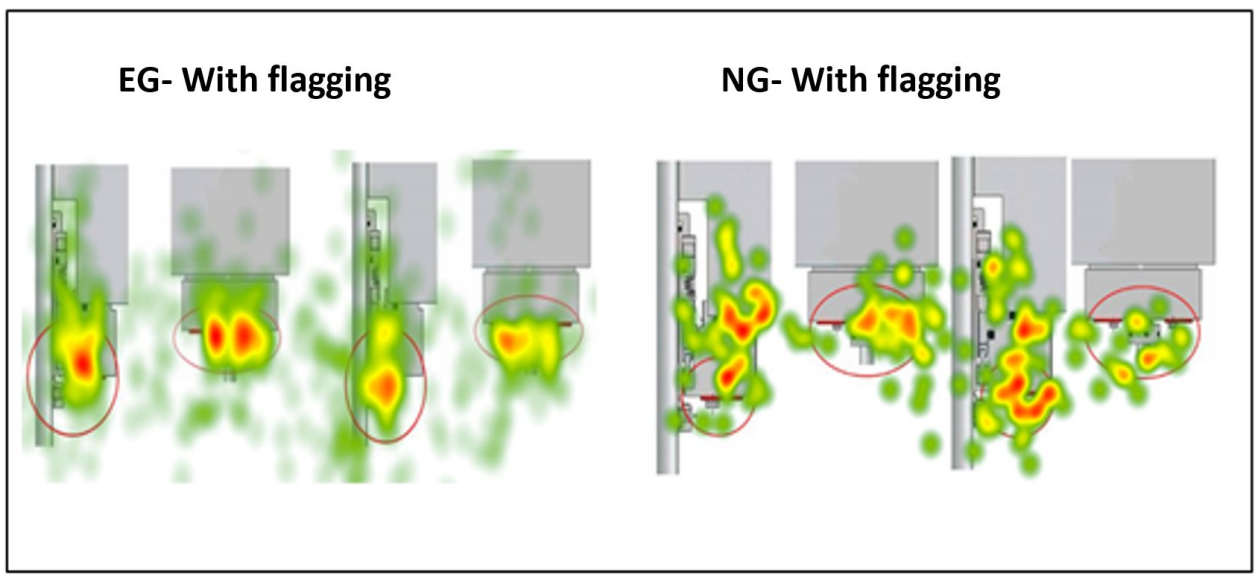

Figure 6. Heatmap of the EG and NG for the flagged procedure. Source: Authors.

Figure 6 shows that in the flagged procedure, the pattern of visual attention is distributed among all stages of the task in both groups. In addition, the red shade is present in all AOls, thus showing that the flagged procedure draws the attention of experts and novices, making them fix their eyes on each stage, without neglecting any stage. Thus, the flagged procedure may enhance visual attention, also favoring the storage of relevant information by coding the task and facilitating memory recall (Izquierdo, 2011; Ramey et al., 2019; Sternberg, 2010).

\section{Conclusion}

The results indicated some similarities and differences in the visual attention of experts and novices when using the two prescribed work procedure models: with and without flagging. In the nonflagged procedure, novices were less confident because they showed a higher number of fixations on and visits to AOls in both the initial viewing and full session. Conversely, in the flagged procedure, experts and novices fixed their eyes similarly and on all stages of the task (AOls) in the full session, as shown in the heatmap. However, in the experiment that analyzed first fixations, attention differed between the flagged and the nonflagged procedures in both groups, thus indicating the need for revising the task regarding the most relevant points that should be observed and inspected during mechanical seal assembly and/or installation.

In conclusion, although experts showed more confidence than did novices in paying attention to the relevant points during mechanical seal assembly and installation, work performance must still be revised in both groups. In addition, the results showed that the flagged procedure can be used as a guide for task monitoring, helping workers, 
whether experts or novices, to select relevant information that can be more easily retrieved from memory.

Among the limitations of this study, the following stand out: the limited sample size, the difficulty in obtaining expert and novice groups with similar average ages and the use of an on-screen procedure simulating the task at the pump. Furthermore, several studies relate pupil dilation to the level of cognitive load and to the complexity and difficulty of performing the task. However, this approach was not used in this study.

Future studies should assess whether the actual conditions of field activities, using mobile eye trackers, can improve the attention span of task performers. Other resources could also be included in the data collection and analysis procedure of new studies, such as sound stimuli, think-aloud protocols and interviews, among others, to further the eye-tracking findings.

Although task viewing with the flagged procedure, in the full session of the experiment, indicated a more homogeneous pattern between experts and novices, the results from the onset of viewing suggest the need for further understanding, in future research, the inconsistency of points of attention of experts in the procedure before and after flagging.

\section{Acknowledgements}

The authors are grateful for the relevant collaboration of Prof. David Saldaña, leader of the Laboratory of Diversity, Cognition and Language at the Universidad de Sevilla (Spain), for the opportunity to present the studies with eye tracking that have been conducted with his research group, enabling learning and experience with the application of technology.

\section{References}

American Petroleum Institute - API. (2001). API 770: manager's guide to reducing human errors: improving human performance in the process industries. Washington: API.

American Petroleum Institute - API. (2004). Standard 682: pumps: shaft sealing centrifugal and rotary pumps. Washington: API.

Barreto, A. M. (2012). Eye tracking como método de investigação aplicado às ciências da comunicação. Revista Comunicando, 1(1), 168-186.

Bauer, R. C., \& Weiner, R. (2010). Estratégias cognitivas aplicadas à prevenção de acidentes aeronáuticos. Revista Conexão SIPAER, 2(1), 97-129.

Bear, M. F., Connors, B. W., \& Paradiso, M. A. (2008). Neurociências: desvendando o sistema nervoso. Porto Alegre: Artmed.

Boyer, T., \& Wang, M. (2018). Direct gaze, eye movements, and covert and overt social attention processes. Attention, Perception \& Psychophysics, 80(7), 1654-1659. http://dx.doi.org/10.3758/s13414-018-1590-z. PMid:30155801.

Brandão, M. L. (2004). As bases biológicas do comportamento: introdução à neurociência. São Paulo: Editora Pedagógica e Universitária.

Carvalho, A. L., \& Menegon, N. L. (2014). A pertinência dos documentos prescritos nas atividades dos profissionais de manutenção industrial: o caso de uma indústria automobilística. Gestão \& Produção, 21(1), 143-155. http://dx.doi.org/10.1590/S0104$530 \times 2014000100010$. 
Charness, N., Reingold, E. M., Pomplun, M., \& Stampe, D. M. (2001). The perceptual aspect of skilled performance in chess: evidence from eye movements. Memory \& Cognition, 29(8), 1146-1152. http://dx.doi.org/10.3758/BF03206384. PMid:11913751.

Chelazzi, L., Perlato, A., Santandrea, E., \& Della Libera, C. (2013). Rewards teach visual selective attention. Vision Research, 85(7), 58-72. http://dx.doi.org/10.1016/j.visres.2012.12.005. PMid:23262054.

Crundall, D., \& Underwood, G. (2011). Visual attention while driving: measures of eye movements used in driving research. In B. E. Porter (Ed.), Handbook of traffic psychology (pp. 137-148). San Diego: Academic Press, Elsevier Inc. http://dx.doi.org/10.1016/B978-012-381984-0.10011-6.

Duchowski, A. (2007). Eye tracking methodology: theory and practice. Cham: Springer.

Duchowski, A. T. (2002). A breadth-first survey of eye-tracking applications. Behavior Research Methods, Instruments, \& Computers, 34(4), 455-470. http://dx.doi.org/10.3758/BF03195475. PMid:12564550.

Duchowski, A. T., Medlin, E., Gramopadhye, A., Melloy, B., \& Nair, S. (2001). Binocular eye tracking in VR for visual inspection training. In VRST '01 Proceedings of the ACM Symposium on Virtual Reality Software and Technology (pp. 1-8). New York: ACM Press. http://dx.doi.org/10.1145/505008.505010.

Dzeng, R.-J., Lin, C.-T., \& Fang, Y.-C. (2016). Using eye-tracker to compare search patterns between experienced and novice workers for site hazard identification. Safety Science, 82, 56-67. http://dx.doi.org/10.1016/j.ssci.2015.08.008.

Embrey, D. (2000). Preventing human error: developing a consensus led safety culture based on best practice. Lancashire: Human Reliability Associates Ltda. Retrieved in 2009, December 21, from http://www.humanreliability.com/articless

Figueiroa, C. L. S., Fo., \& Souza, M. L. (2011). Confiabilidade humana: a importância da gestão visual nos procedimentos de manutenção. In XXXI Encontro Nacional de Engenharia de Produção (ENEGEP): Inovação Tecnológica e Propriedade Intelectual (pp. 1-11). Belo Horizonte: ABEPRO.

French, S., Bedford, T., Pollard, S. J. T., \& Soane, E. (2011). Human reliability analysis: a critique and review for managers. Safety Science, 49(6), 753-763. http://dx.doi.org/10.1016/j.ssci.2011.02.008.

Giesbrecht, B., Sy, J., Bundesen, C., \& Kyllingsbaek, S. (2014). A new perspective on the perceptual selectivity of attention under load. Annals of the New York Academy of Sciences, 1316(1), 71-86. http://dx.doi.org/10.1111/nyas.12404. PMid:24716751.

Gómez-Valadés, J. M., Luis, V., Reina, R., Sabido, R., \& Moreno, F. J. (2013). Estrategias de búsqueda visual en conductores expertos y noveles durante la visualización de escenas de tráfico. Anales de Psicología, 29(1), 272-279.

http://dx.doi.org/10.6018/analesps.29.1.132351.

Guerra-Carrillo, B. C., \& Bunge, S. A. (2018). Eye gaze patterns reveal how reasoning skills improve with experience. NPJ Science of Learning, 3(1), 18. http://dx.doi.org/10.1038/s41539-018-0035-8. PMid:30631479.

Haider, H., \& Frensch, P. A. (1999). Eye movement during skill acquisition: more evidence for the information-reduction hypothesis. Journal of Experimental Psychology. Learning, Memory, and Cognition, 25(1), 172-190. http://dx.doi.org/10.1037/0278-7393.25.1.172.

Henriqson, E., \& Saurin, T. A. (2013). Análise do campo conceitual da engenharia de sistemas cognitivos e proposta de uma nova agenda de pesquisa. Production, 24(2), 405-419. http://dx.doi.org/10.1590/S0103-65132013005000056.

Hollingworth, A., \& Maxcey-Richard, A. M. (2013). Selective maintenance in visual working memory does not require sustained visual attention. Journal of Experimental Psychology. Human Perception and Performance, 39(4), 1047-1058. http://dx.doi.org/10.1037/a0030238. PMid:23067118. 
Ikuma, L. H., Harvey, C., Taylor, C. F., \& Handal, C. (2014). A guide for assessing control room operator performance using speed and accuracy, perceived workload, situation awareness, and eye tracking. Journal of Loss Prevention in the Process Industries, 32, 454-465. http://dx.doi.org/10.1016/j.jp.2014.11.001.

Izquierdo, I. (2011). Memória. Porto Alegre: Artmed.

Jarodzka, H., Scheiter, K., Gerjets, P., \& van Gog, T. (2010). In the eyes of the beholder: how experts and novices interpret dynamic stimuli. Journal Learning and Instruction, 20(2), 146154. http://dx.doi.org/10.1016/j.learninstruc.2009.02.019.

Kardec, A., \& Nascif, J. (2005). Manutenção: função estratégica. Rio de Janeiro. Qualitymark.

Koller, M., Salzberger, T., Brenner, G., \& Walla, P. (2012). Broadening the range of applications of eye-tracking in business research. Análise, 23(1), 71-77.

Le, Q. T., Lee, D. Y., \& Park, C. S. (2014). A social network system for sharing construction safety and health knowledge. Automation in Construction, 46, 30-37. http://dx.doi.org/10.1016/j.autcon.2014.01.001.

Lima, E. P. C. (2003). Mecânica das bombas. Rio de Janeiro: Interciência.

Martins, M. P. S. (2008). Estudo de fatores humanos e observação dos seus aspectos básicos, focados em operadores do reator de pesquisa IEA-R1, objetivando a prevenção de acidentes ocasionados por falhas humanas (Dissertation). Instituto de Pesquisas Energéticas e Nucleares, São Paulo.

Montes, S. A., Introzzi, I. M., Ledesma, R. D., \& López, S. S. (2016). Atención selectiva y propensión al error en la conducción: estudio mediante una tarea de búsqueda visual conjunta. Avances en Psicología Latinoamericana, 34(2), 195-203. http://dx.doi.org/10.12804/apl34.2.2016.01.

Pallerosi, C. A., Mazzolini, B. P. M., \& Mazzolini, L. R. (2011). Confiabilidade humana: conceitos, análise, avaliações e desafios. Ribeirão Pires: All Print Editora.

Ramey, M. M., Yonelinas, A. P., \& Henderson, J. M. (2019). Conscious and unconscious memory differentially impact attention: eye movements, visual search, and recognition processes. Cognition, 185, 71-82. http://dx.doi.org/10.1016/j.cognition.2019.01.007. PMid:30665071.

Rayner, K. (1998). Eye movements in reading and information processing: 20 years of research. Psychological Bulletin, 124(3), 372-422. http://dx.doi.org/10.1037/00332909.124.3.372. PMid:9849112.

Reason, J. (1990). Human error. Cambridge: Cambridge University Press. http://dx.doi.org/10.1017/CBO9781139062367.

Romo, G. M. (2013). Improving human performance: industry factors influencing the ability to perform. Knowledge Management \& E-Learning: An International Journal, 5(1), 66-83.

Salehi, S., Kiran, R., Jeon, J., Kang, Z., Cokely, E. T., \& Ybarra, V. (2018). Developing a crossdisciplinary, scenario-based training approach integrated with eye tracking data collection to enhance situational awareness in offshore oil and gas operations. Journal of Loss Prevention in the Process Industries, 56, 78-94. http://dx.doi.org/10.1016/j.jp.2018.08.009.

Sheikhalishahi, M., Pintelon, L., \& Azadeh, A. (2016). Human factors in maintenance: a review. Journal of Quality in Maintenance Engineering, 22(3), 218-237. http://dx.doi.org/10.1108/JQME-12-2015-0064.

Silva, J. A. P., \& Camarotto, J. A. (2012). Human reliability in petrochemical industry: an action research. Work, 41(1, Suppl. 1), 3325-3332. http://dx.doi.org/10.3233/WOR-2012-10343325. PMid:22317223.

Sternberg, R. J. (2010). Psicologia cognitiva. São Paulo: Cengage Learning.

Tobii. (2013). Tobii X2-30 eyetracker user'smanual version 1.0.0. Suécia: Tobii Technology AB. 
van den Bogert, N., van Bruggen, J., Kostons, D., \& Jochems, W. (2014). First steps into understanding teachers' visual perception of classroom events. Teaching and Teacher Education, 37, 208-216. http://dx.doi.org/10.1016/j.tate.2013.09.001.

van Rijn, S., Urbanus, E., \& Swaab, H. (2019). Eyetracking measures of social attention in young children: how gaze patterns translate to real-life social behaviors. Social Development, 28(3), 564-580. http://dx.doi.org/10.1111/sode.12350.

Vijayan, K. K., Mork, O. J., \& Hansen, I. E. (2018). Eye tracker as a tool for engineering education. Universal Journal of Educational Research, 6(11), 2647-2655.

http://dx.doi.org/10.13189/ujer.2018.061130. 